\title{
Effect of surface and heat treatment on tensile properties of jute fiber reinforced composite
}

\author{
K. Takemura \\ Department of Mechanical Engineering, Kanagawa University, Japan
}

\begin{abstract}
In this study, the tensile properties of Fiber Reinforced Plastics (FRP) using natural fibers were investigated. Jute fibers were chosen as reinforcement. Polypropylene was used as a matrix. Jute Fiber Reinforced Plastics (JFRP) was laminated using a conventional hot press facility. The surface treatment using the astringency of persimmon was performed on the jute fiber before molding. The surface treatment using heat treatment to jute fiber in an oven was also conducted. The static tensile and creep properties of jute fiber reinforced composite were investigated.

As a result, the following conclusions are obtained.

(1) The treatment using the astringency of persimmon is effective to improve the interfacial strength between jute fiber and the matrix and it decreases the initial elastic strain in a creep test. (2) For a static tensile test, the treatment using the astringency of persimmon increases the initial stiffness. The improvement ratio decreases as the applied load increases. (3) The treatment using heating fibers before molding has an effect in that it increases the tensile strength and initial stiffness, because the treatment improves the interfacial strength between the fiber and the matrix. (4) The effect of heat treatment is the highest in the case where the temperature is 120 degrees centigrade and the time is half an hour.

Keywords: green composite, jute fiber, polypropylene, tensile properties, creep, surface treatment, heat treatment.
\end{abstract}

\section{Introduction}

Glass Fiber Reinforced Plastics (GFRP) have been popular for many mechanical parts. Because of their superior advantages, such as durability, high specific strength, stiffness, GFRPs have been replaced instead of metals in many 
applications. Recently, there has been a waste problem concerning fishing boats, etc. Glass fiber has high chemical stability, and it is also difficult to be burned out. So, composite materials, particularly using thermoset resins are almost impossible to be recycled or reused. As the solution of such problems, there is a lot of interest in developing green composites. These green composites are defined by fully sustainable, biodegradable environment friendly and renewable fibers which are called natural fibers.

Recently, there have been some studies on manila hemp, bamboo fibers as reinforcement of green composites. Manila hemp fiber reinforced composite has a high strength which is above $350 \mathrm{MPa}[1,2]$. But it has a problem for the high cost and a small market. For bamboo fiber reinforced composite, there are a lot of studies about mechanical properties [3-5]. The Fifth International Workshop for Green Composites was held in 2008 in Japan. So, many researchers were interested in this issue $[6,7]$.

Jute is focused on from the viewpoint of cost. And it is easy to get jute fibers from the general market so JFRP is used in this study. The static tensile tests for this composite are conducted in order to examine strength and stiffness. Natural fiber has been used as fishing nets for a long time in Japan. Many chemical treatment methods have been performed on the natural fibers. Among them, the astringency of a persimmon has been used for improving the surface of natural fibers. So, the surface treatment method is conducted for this natural fiber using the astringency of a persimmon. The surface treatment using heat treatment to jute fiber in an oven is also conducted. Static tensile test and creep properties for JFRP are investigated.

\section{Specimen and experimental procedure}

\subsection{Specimen}

Plain woven jute fabric was used as reinforcement. The directions of jute fibers are parallel and perpendicular to a load direction. Polypropylene resin sheet (Shin Kobe Electric Inc. PP-N-AN) was used as a matrix. The plate of the composite was molded with a conventional hot pressing technique (Toyo Seiki Co., Mini Test Press MP-WCL). To process the composite, jute fabric sheets were put into the metallic mold. The mold with material was vacuumed with a heat resisting film bag in the process.

The geometry of specimens is referenced to JIS (Japanese Industrial Standard) 7054. The length of the specimen is $200 \mathrm{~mm}$. The breadth and thickness are $10 \mathrm{~mm}$ and $2.5 \mathrm{~mm}$ respectively.

\subsection{Surface treatment using the astringency of a persimmon}

For a surface treated specimen, the plain woven fabric was laid in the solution of astringent persimmon. The density of the solution was $25 \%$. After absorbing the solution, the fabric was dried in an oven for five hours. 


\subsection{Heat treatment before molding}

Jute fabrics were laid in an oven and they were dried before molding. Four kinds of time $0.25 \mathrm{~h}, 0.5 \mathrm{~h}, 0.75 \mathrm{~h}$ and $1.0 \mathrm{~h}$ were used. And four kinds of heat temperature $80,100,120$ and 140 degrees centigrade were used.

\subsection{Static tensile and creep tests}

The Shimadzu autograph tensile test machine (AG-IS) was used for the static tensile tests. The test condition is referenced to JIS7054. The crosshead speed was $1.0 \mathrm{~mm} / \mathrm{min}$.

The Creep Tester 100LER (Toyo Seiki. Co.) was used for creep tests. This test is referenced to JIS7087. The test is continued by a failure of specimen. When a specimen does not fail, the creep test stops at 100 hours. Three specimens can be conducted simultaneously in this test machine. Creep strains were measured throughout the test. Before the test, the surfaces of the composite are observed using Scanning Electron Microscope (SEM) to confirm the effect of the treatments.

\section{Results and discussion}

\subsection{Tensile creep properties for surface treatment}

Figure 1 shows the tensile creep curves when the applied loads are $200 \mathrm{~N}, 300 \mathrm{~N}$ and $400 \mathrm{~N}$. In this figure $\mathrm{U}$ means untreated data, and $\mathrm{K}$ means treated data using

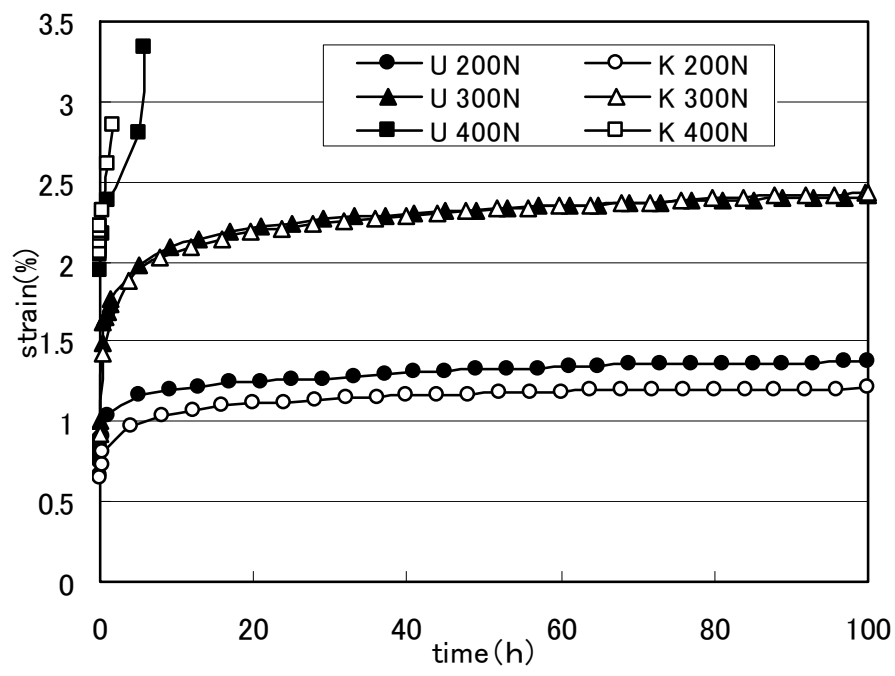

Figure 1: $\quad$ Comparison of untreated (U) and surface treated (K) JFRPs. 
the astringency of a persimmon. When the applied loads are $300 \mathrm{~N}$ and $400 \mathrm{~N}$, the curves have a transit creep region and steady creep region, and specimens do not fail. On the other hand, when the applied load is $400 \mathrm{~N}$, they also have an acceleration creep region, and specimens fail in several hours after the test started. When the applied load is $400 \mathrm{~N}$, the treated specimen fails faster that untreated specimen. When the applied load is $300 \mathrm{~N}$, there is no distinct difference between either curve. On the other hand, the strain of treated specimen is smaller than that of untreated specimen when the applied load is $200 \mathrm{~N}$. Especially, the treatment affects the elastic strain. So, when the applied load is relatively low, the effect of surface treatment is emerging.

\subsection{Static tensile properties for surface treatment}

Figure 2 shows the stress-strain curves for untreated and surface treated JFRPs. Table 1 shows the Young's modulus when the strain is 0.05 and 2.0 percent. From this figure and table, the initial stiffness for treated JFRP can be seen to be bigger than that of untreated JFRP. As the strain increases, the difference of both stiffness decreases.

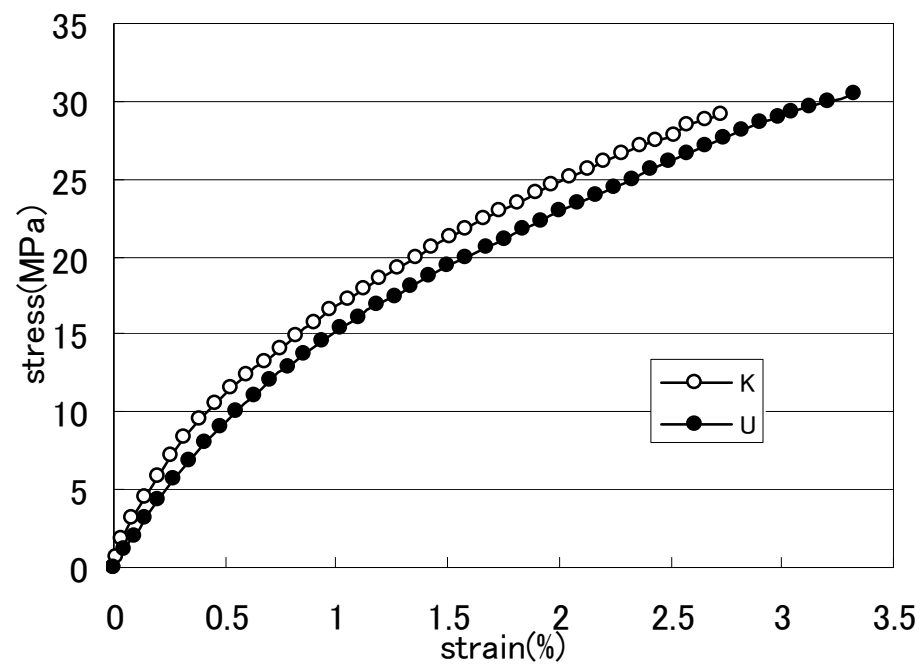

Figure 2: $\quad$ Stress-strain curves for untreated(U) and surface treated (K) JFRPs.

Table 1: Young's modulus of JFRP with surface treatment.

\begin{tabular}{|c|c|c|c|}
\hline \multicolumn{2}{|c|}{ Strain } & $0.05 \%$ & $2.0 \%$ \\
\hline $\begin{array}{c}\text { Young's } \\
\text { modulus } \\
(\mathrm{GPa})\end{array}$ & Treated & 2.39 & 0.67 \\
\cline { 2 - 4 } & Untreated & 2.03 & 0.66 \\
\hline
\end{tabular}


So, this surface treatment is effective to the initial stiffness. For the creep test which is already mentioned, when the applied load is low, the effect of the surface treatment is distinct. This phenomenon of initial stiffness is thought to be the reason for the difference on creep strains.

\subsection{Observation of jute fibers after surface treatment by SEM}

Figure 3(a), (b) show the SEM photographs of untreated and treated jute fibers. From the photographs, it is understood that the untreated fibers do not make fiber bundles, but the treated fibers can make fiber bundles. Astringent persimmon has tannin which makes a skin layer on the fiber surface, so the surface of fibers is thought to be sticky. It is thought to be the reason that the initial stiffness increases.

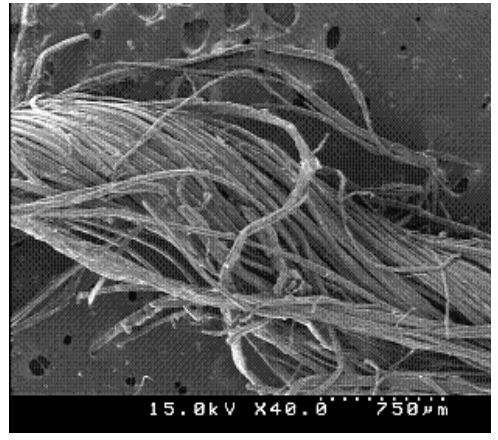

(a) untreated jute fiber

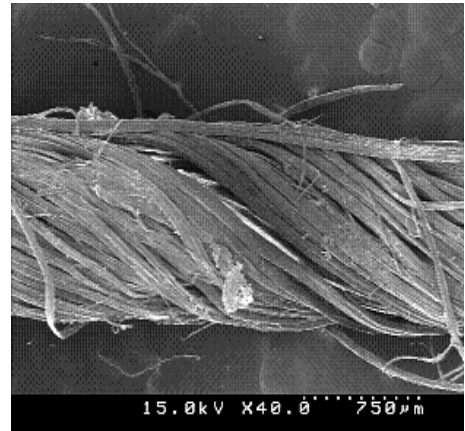

(b) treated jute fiber

Figure 3: $\quad$ SEM photographs of jute fibers with surface treatment.

\subsection{Tensile properties of JFRP using heat treated jute fiber}

Figure 4(a)-(d) show the stress-strain curves for heat treated and untreated JFRP. Table 2 shows the tensile strength and stiffness. When the heat temperatures are $80,100,120$ degrees centigrade, and heating times are $0.25,0.5,1.0$ hours, the tensile strength and stiffness are improved by heat treatment. In these cases, the case where the heating time is 0.5 hour, the effect is great. On the other hand, when the heating temperature is 140 degrees centigrade, the effective condition is only the case when the heating time is 0.5 hour. In this case, the effect is smaller than that of 120 degrees centigrade. The strength of bamboo fibers and manila hemp fibers decreases due to heat resolution above 140 and 160 degrees centigrade, respectively. The strengths of both fibers decrease $60 \%$ at 200 degrees centigrade. The strength of jute fiber is thought to decrease around 140 degrees centigrade. So, the decrease in strength for JFRP is due to a heat resolution around 140 degrees centigrade. In this temperature condition, the effect is the highest when the heat time is 0.5 hour. When the heating time is longer than 0.5 hour, there is no effect. This is because that heat resolution is dependent on the heating time in the conditions. 
172 High Performance Structures and Materials V

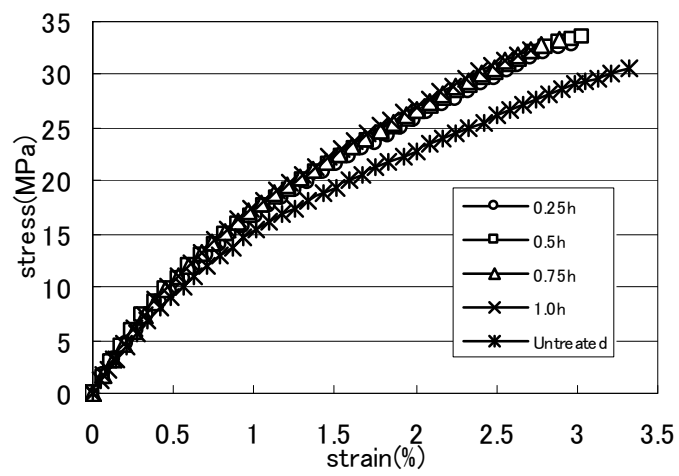

(a) $80^{\circ} \mathrm{C}$

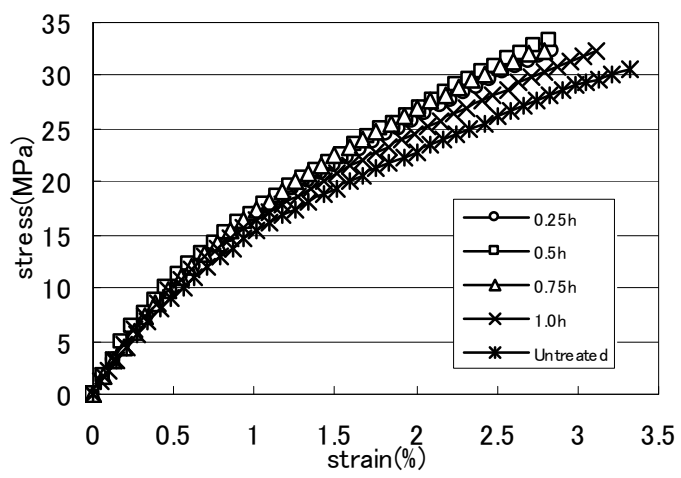

(b) $100^{\circ} \mathrm{C}$

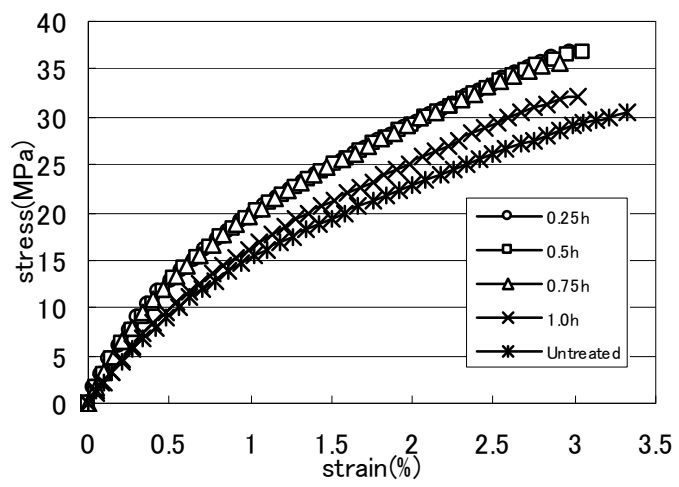

(c) $120^{\circ} \mathrm{C}$

Figure 4: $\quad$ Stress-strain curves of JFRP with heat treatment. 


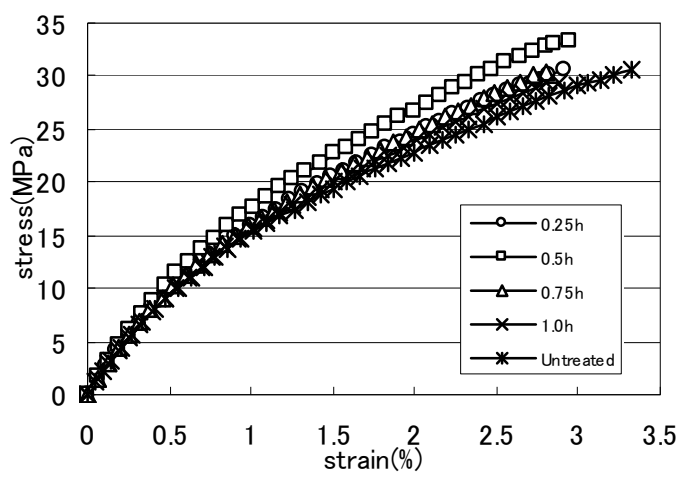

(d) $140^{\circ} \mathrm{C}$

Figure 4: Continued.

\subsection{Observation of jute fibers after heat treatment}

Figure 5(a), (b) show the SEM photographs of untreated and heat treated jute fibers. The treatment condition was that the heating temperature was 120 degrees centigrade and heating time was 0.5 hour. From these photographs, it is understood that untreated fibers does not have form a fiber bundle and treated fibers form a better bundle. Natural fibers have many voids in it and it can absorb moisture. At heating treatment, the moisture in jute fiber vapors. So the resin can penetrate between fibers at molding. So, the strength and stiffness is thought to be increased by heat treatment. The reason why the effect of heat treatment increases as treatment temperature increase, the vaporization is more activated at high temperature condition. As a result, the strength at the interface between fibers and matrix is thought to be high. Furthermore, the reason the effect of 0.5 hour is bigger than that of 0.25 hour, is also the water vaporization in jute fibers.

Table 2: Tensile properties of JFRP with heat treatment.

\begin{tabular}{|c|c|c|c|c|c|}
\hline & & $0.25 \mathrm{~h}$ & $0.5 \mathrm{~h}$ & $0.75 \mathrm{~h}$ & $1.0 \mathrm{~h}$ \\
\hline \multirow{5}{*}{$\begin{array}{c}\text { Tensile } \\
\text { strength } \\
\text { (MPa) }\end{array}$} & $80^{\circ} \mathrm{C}$ & 32.9 & 33.6 & 33.2 & 32.2 \\
\hline & $100^{\circ} \mathrm{C}$ & 32.3 & 33.4 & 32.4 & 32.6 \\
\hline & $120^{\circ} \mathrm{C}$ & 36.0 & 36.7 & 35.7 & 32.2 \\
\hline & $140^{\circ} \mathrm{C}$ & 30.5 & 33.3 & 30.5 & 29.5 \\
\hline & Untreated & \multicolumn{4}{|c|}{30.5} \\
\hline \multirow{5}{*}{$\begin{array}{c}\text { Young's } \\
\text { modulus } \\
(\mathrm{GPa})\end{array}$} & $80^{\circ} \mathrm{C}$ & 2.13 & 2.30 & 2.30 & 2.30 \\
\hline & $100^{\circ} \mathrm{C}$ & 2.14 & 2.47 & 2.27 & 2.22 \\
\hline & $120^{\circ} \mathrm{C}$ & 2.80 & 2.83 & 2.78 & 2.14 \\
\hline & $140^{\circ} \mathrm{C}$ & 2.06 & 2.31 & 2.16 & 2.03 \\
\hline & Untreated & \multicolumn{4}{|c|}{2.03} \\
\hline
\end{tabular}




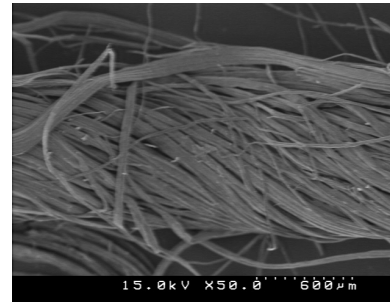

(a) untreated

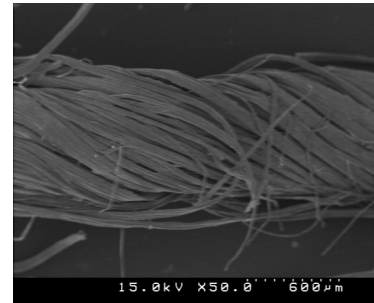

(b) heated

Figure 5: $\quad$ SEM photographs of jute fiber with heat treatment.

\section{Conclusions}

As a result, the following conclusions are obtained.

(1) The treatment using the astringency of persimmon is effective to improve the interfacial strength between jute fiber and matrix and it decreases the initial elastic strain in creep test. (2) For the static tensile test, the treatment using the astringency of persimmon increases the initial stiffness. The improvement ratio decreases as the applied load increases. (3) The treatment using heating the fibers before molding has an effect where it increases the tensile strength and initial stiffness because the treatment improves the interfacial strength between fiber and matrix. (4) The effect using heat is the highest in the case where the temperature is 120 degrees centigrade and the time is half an hour.

\section{References}

[1] S. Ochi, Development of high strength biodegradable composites using manila hemp fiber and starch-based biodegradable resin, Appl. Sci. Manuf. 37(2006), pp.1879-1883

[2] S. Ochi, H. Takagi and H. Tanaka, Tensile properties of manila hemp reinforced cross-ply "green" composites, J. Soc. Mater. Sci. 52 (2003), pp. 916-921

[3] S. Lee and S. Wang, Biodegradable polymers/bamboo fiber biocomposite with bio-based coupling agent, Appl. Sci. Manuf. 37(2006), pp. 80-91

[4] H. Takagi and R. Takura, The manufacture and mechanical properties of composite boards made from starch-based biodegradable plastic and bamboo powder, J. Soc. Mater. Sci. 52(2003), pp. 357-361

[5] H. Takagi and Y. Ichihara, Effect of fiber length on mechanical properties of "green" composites using a starch-based resin and short bamboo fibers, JSME. 47 4(2004), pp. 551-555 
[6] K. Tanaka, Y. Masabe and T. Katayama., Mechanical Properties of Jute Fabric Reinforced PLA Nonwoven Sheet Composite, Proc. of Fifth Int. Workshop on Green Composites(2008), pp. 37-41

[7] H. Takagi and Y. Hagiwara, Microfracture Behavior of Hemp FiberReinforced Green Composite, Proc. of Fifth Int. Workshop on Green Composites (2008), pp. 23-26 